\title{
The effects of signaling the US in backward conditioning: A shift from excitatory to inhibitory learning
}

\author{
JOHN C. DOLAN, AKIRA SHISHIMI, and ALLAN R. WAGNER \\ Yale University, New Haven, Connecticut
}

\begin{abstract}
The associative effects of "backward" US-CS pairings were compared when the pairing occasions were either consistently preceded by a well-trained CS+ or were unannounced. The investigation employed a conditioned emotional response procedure with rats, under conditions in which all subjects received the same schedule of shock USs, some signaled and others not, and the backward CS was arranged to follow either the former or the latter, in separate groups. The major finding was that although the backward CS became excitatory when it followed unsignaled USs, it became inhibitory when it followed signaled USs. This outcome, which is in line with prior findings of Wagner and Terry (1975), is in accordance with a "sometimes-opponent-process" model proposed by Wagner (1981). It is contrary to data reported by Fowler, Kleiman, and Lysle (1984) that may have resulted from a confounding of the different circumstances of backward conditioning with differences in the predictability of the US in the experimental context.
\end{abstract}

A Pavlovian training regime involving the "backward" sequence of an unconditioned stimulus (US) followed by a conditioned stimulus (CS) can result either in responding to the CS in a fashion similar to that seen with forward pairings (e.g., Heth \& Rescorla, 1978; Keith-Lucas \& Guttman, 1975) or in a tendency for the CS to oppose such responding (e.g., Maier, Rapaport, \& Wheatley, 1976; Siegel \& Domjan, 1971). Historically, there has been considerable resistance to accepting the behavioral products as associative consequences specifically attributable to the backward pairings involved, and there are clearly other potential bases for the effects (see, e.g., Mackintosh, 1974, and Spetch, Wilkie, \& Pinel, 1981, for reviews). However, recent theoretical treatments have been more inclined to accept both excitatory associative learning (Heth, 1976; Wagner \& Terry, 1975) and inhibitory associative learning (e.g., Schull, 1979; Wagner \& Larew, 1985) as genuine results of backward pairings, per se, and to attempt to rationalize the conditions under which one or the other may predominate (e.g., Mazur \& Wagner, 1982).

Mazur and Wagner (1982) have assumed that stimulus processing involves two phases, an initial memorial activity (A1) and a secondary memorial activity (A2). When a CS and US are "paired," that is, presented in close temporal relationship, it is presumed that the CS will become an excitatory stimulus in relationship to the US to the

The study reported was supported in part by National Science Foundation Grant BNS 80-23399 to Allen R. Wagner. Akira Shishimi is now at Hiroshima Shudo University, Hiroshima, Japan. Requests for reprints should be addressed to Allan R. Wagner, Department of Psychology, Yale University, New Haven, CT 06520. degree that the Al processing of the CS overlaps the A1 processing of the US, but will become an inhibitory stimulus to the degree that the same Al processing of the CS overlaps the A2 processing of the US. The overall behavioral result of the pairing is assumed to reflect the summed consequences of the separable excitatory and inhibitory tendencies that thus accrue. It should be obvious, on these assumptions, that forward pairings would be more likely to produce a net excitatory effect than would backward pairings, and that backward pairings could variously have a net excitatory or net inhibitory effect, depending upon the specific conditions of training.

The research to be reported is concerned with the further implications of companion assumptions (e.g., Wagner, 1981), which suppose that an excitatory CS instigates the A2 processing of the US it signals and, as a consequence, decreases the A1 processing that can then be provoked by the US itself. On this reasoning, along with the association rules of Mazur and Wagner (1982), it would be predicted that a backward US-CS pairing that was immediately preceded by a well-trained $\mathrm{CS}+$ would produce less excitatory learning (due to the diminished A1 processing of the US that is afforded) and potentially occasion more inhibitory learning (due to the persisting A2 processing of the US initiated by $\mathrm{CS}+$ ) than would a similar pairing that was unannounced. In brief, the consequence of signaling the US of a backward, US-CS, pairing should be to shift the net balance of associative effects of the training episode from excitatory toward inhibitory.

The resuits of a study by Wagner and Terry (1975) are consistent with this expectation. Wagner and Terry used a rabbit eyeblink conditioning preparation and a within- 
subjects comparison in which subjects experienced one CS in backward pairings with a US that was itself preceded by a well-trained CS+ and another CS in backward pairings with an "unsignaled" US (actually, preceded by a discriminated CS-). What was observed was that subjects developed substantial excitatory conditioned eyeblink responding to the backward CS in the unsignaled case but none in the signaled case. Wagner and Terry did not assess any inhibitory tendencies that may have accrued to the backward CSs. But it would be expected that such tendencies would have been more likely to have been observed to the CS that was paired with the signaled as opposed to the unsignaled US.

In this context, the results of a recent study by Fowler, Kleiman, and Lysle (1984) may appear discordant. These investigators used rats in a conditioned emotional response (CER) paradigm and a between-subjects comparison, in which one group experienced a CS in backward pairings with a signaled US and another group experienced the same CS in backward pairings with an unsignaled US. They subsequently assessed the associative effects of the backward cue in a retardation test. What was observed was that the backward CS becomes demonstrably inhibitory in the unsignaled case but not in the signaled case. Signaling did not appear to shift the balance of backward conditioning effects toward being less excitatory and/or more inhibitory, as predicted from the account of Wagner (1981) and Mazur and Wagner (1982), and as could be thought to have occurred in the Wagner and Terry (1975) study, but, rather, produced less evidence of inhibitory learning.

It should be noted, however, that the Fowler et al. (1984) study differed from that of Wagner and Terry (1975) in an important way that may have complicated the outcome. Wagner and Terry used a within-subjects comparison, whereas Fowler et al. used a between-groups comparison. How this may be important should be apparent, if it is appreciated that inhibitory learning is commonly assumed (e.g., Wagner, 1981; Wagner \& Rescorla, 1972) to be caused by treatments that lead a CS to be experienced in an excitatory environmental context, and that unsignaled USs have been demonstrated (e.g., Odling-Smee, 1978) to produce more excitatory conditioning of the context than do explicitly signaled USs. The corollary of Fowler et al.'s use of a between-groups comparison was that the group that received backward pairings involving unsignaled USs consistently received only unsignaled USs that should have produced an excitatory experimental context for the target CS. In contrast, the group that received backward pairings involving signaled USs consistently received only signaled USs that should have produced a less excitatory experimental context for the target CS. Thus, in the absence of any associative effects of the backward pairings, per se, it could be expected that the unsignaled treatment would have produced more inhibitory learning to the target CS than would the signaled treatment. LoLordo and Fairless (1985) have made the same point in regard to unpublished studies by LaClerc and by Overmier and Peterson, similar in design to that of Fowler et al. By comparison, Wagner and Terry embedded the signaled versus unsignaled backward conditioning trials in the same overall sequence of trials, within subjects, to eliminate potentially obscuring effects of differences in contextual conditioning. In the theoretical language of Mazur and Wagner (1982), Wagner and Terry arranged to equate the A2 processing of the US that might be instigated by contextual cues contemporaneous with the A1 processing of the CS, to produce inhibitory learning on the occasions of the backward conditioning trials, whereas Fowler et al. employed conditions in which such source of inhibitory learning would be expected to be greater in the unsignaled than in the signaled case.

The experiment to be reported here was designed to allow for an evaluation of the differential inhibitory consequences of signaled versus unsignaled backward conditioning trials, as in the Fowler et al. (1984) study, but in a circumstance in which contextual conditioning could be assumed to be equated, as in the Wagner and Terry (1975) study. It was further patterned after Fowler et al.'s study in involving CER conditioning and similar parameters of stimulation. In specific design, all subjects received the same sequence of USs, some signaled and others not. For one group the target CS was introduced only following the signaled USs, whereas for the other group the target CS was introduced only following the unsignaled USs. It remained to be seen whether the results would follow those of Fowler et al. in spite of the equating of opportunities for contextual conditioning, or would be in line with the findings of Wagner and Terry (1975), as predicted by the theorizing of Mazur and Wagner (1982) and Wagner (1981), to witness a relative shift toward less excitatory learning and more inhibitory learning in the case of signaled as opposed to unsignaled backward pairings.

\section{METHOD}

\section{Subjects}

The subjects were 16 male albino rats, obtained from Charles River Breeders and weighing between 350 and $475 \mathrm{~g}$ at the start of the experiment. The subjects were housed individually with free access to water and were brought to, and maintained at, $75 \%$ of their preexperimental body weights by limited feedings $10 \mathrm{~min}$ after the daily experimental sessions.

\section{Apparatus}

Training and testing were done in eight identical $24 \times 21 \times 19 \mathrm{~cm}$ operant chambers, each enclosed in a $48 \times 48 \times 66 \mathrm{~cm}$ isolation box. The operant chambers were constructed of clear Plexiglas sides and ceiling adjoining two aluminum end walls and a grid floor of $5-\mathrm{mm}$ stainless steel rods spaced $1.9 \mathrm{~cm}$ apart. Each chamber had a food magazine recessed in the center of one end wall and a lever $2 \mathrm{~cm}$ to the left of the magazine. When appropriate to the reinforcement contingencies, leverpress responses were reinforced with a $.045-\mathrm{g}$ Noyes food pellet delivered to the magazine by a Davis PD-109A feeder. A .143-W, 120-V houselight covered with a clear plastic cap was mounted $15 \mathrm{~cm}$ above the grid floor, directly over the food magazine, and provided a continuous low level of illumination. The ambient sound pressure level inside the chamber was maintained at $66 \mathrm{~dB}$ (re $20 \mu \mathrm{N} / \mathrm{m}^{2}$, General Radio sound pressure level meter, 
Model 1551, A scale) by the masking noise of a continuously operated ventilating fan.

The apparatus provided for three CSs, visual, auditory, and vibratory, and an electric-shock US. The visual stimulus was a light interrupted three times per second, generated by a 3-W, 120-V lamp powered through a rheostat adjusted to a nominal setting of $96 \mathrm{~V}$. The lamp was mounted on top of the Plexiglas ceiling, but was shielded so that its light diffusely reflected into the chamber from the white interior walls of the isolation box. The auditory stimulus was a $2000-\mathrm{Hz}$ tone, produced by a BRS Foringer AU-902 audio generator and delivered through a 4 -in. $(10.16-\mathrm{cm})$ speaker. The speaker was mounted on one aluminum end wall of the operant box beneath the level of the grid floor, directly below the food magazine. The tone raised the sound level inside the operant chamber to $75 \mathrm{~dB}$. To allow the presentation of the vibratory CS, each chamber was mounted on a $38 \times 24 \times 2 \mathrm{~cm}$ wooden platform, which in turn was supported by four steel springs selected so as to provide a firm base in resistance to movements of the subjects but to allow oscillation in response to the vibratory stimulus. The vibratory stimulus was produced by the $60-\mathrm{Hz}$ oscillation of an electromagnetic fixture from a hand massager (Valmour, Model 800) mounted on the bottom of the chamber platform. The US was a $1.0-\mathrm{mA}$ scrambled electric shock produced by a Grason-Stadler Model E105S shock generator and delivered through the grid floor. Experimental events were controlled and recorded automatically by electromechanical equipment in an adjoining room.

\section{Procedure}

Pretraining. All subjects were trained to barpress for food reward over 11 daily 1 -h sessions. Following an initial session in which a food pellet was dispensed for each barpress on a continuous reinforcement schedule, the subjects were shifted to a variable-interval 60-sec reinforcement schedule, which remained in effect throughout the rest of the experiment. During each of the last two barpress training sessions, the subjects received two presentations each of the vibratory (V) and tone (T) stimuli, each stimulus being $30 \mathrm{sec}$ in duration. Half the subjects experienced these stimuli in the order V-T-T-V on both days; half experienced them in the order $T-V-V-T$. During stimulus preexposure and all subsequent phases of the experiment, the daily sessions continued to be $60 \mathrm{~min}$ in duration and, except in summation testing (see below), the mean ITI was $12 \mathrm{~min}$ (ranging from 9 to $15 \mathrm{~min}$ ).

Training. There were two phases of CER training, the first to develop the light $\mathrm{CS}$ as a reliable signal (designated CS+) for the shock US and the second to provide differential backward conditioning experiences between one of the remaining cues and either signaled or unsignaled USs. The initial phase consisted of three training sessions, each comprising four presentations of a light terminating with a .5-sec US, for a total of $12 \mathrm{CS}+$ pairings. Two sessions of food-rewarded barpress training were inserted after the second CER session in an attempt to recover stable baseline rates of responding after the introduction of the shock US; and such baseline recovery sessions were added to the subsequent session sequence for all subjects, as deemed necessary.

Backward conditioning was administered over 12 sessions. In each session, there were four presentations of the US, two preceded by CS+, as in the prior phase, and two unsignaled. For all subjects, the signaled or unsignaled nature of the first US of the session, as well as the nature of the USs within each session, followed different ABBA sequences so that the first-order transitional probabilities for signaled and unsignaled USs were equated within blocks of four sessions. For all subjects, termination of two of the daily USs was immediately followed by a 30-sec "backward" CS (designated $\mathrm{CS}_{\mathrm{bk}}$ ), other than the light.

The subjects were divided into two equal groups $(\mathrm{Ns}=8)$, matched for baseline rates of barpressing, for differential treatment in this phase. For subjects in the signaled group, $\mathrm{CS}_{\mathrm{bk}}$ was scheduled to occur following the two signaled USs of the session and not after the two unsignaled USs; for subjects in the unsignaled group, $\mathrm{CS}_{\mathrm{bk}}$ was scheduled to occur following the two unsignaled USs of the session and not after the two signaled USs. For half of the subjects in each of these treatment groups, $\mathrm{CS}_{\mathrm{bk}}$ was the tone; for the remaining half of the subjects, it was the vibratory stimulus. The alternate, tone or vibratory stimulus, for each subject was not presented during CER training so that it could be presumed to be associatively relatively neutral (and designated $C S_{n}$ ) relative to $C S_{b k}$ at the time of testing.

Testing. All testing involved nonreinforced stimulus presentations while subjects were barpressing. In an initial test session, designed to comment on the suppressive effects of $\mathrm{CS}_{\mathrm{bk}}$ and $\mathrm{CS}_{\mathrm{n}}$ alone, there were two presentations of $\mathrm{CS}_{\mathrm{bk}}$ and of $\mathrm{CS}_{\mathrm{n}}$ in counterbalanced ABBA orders. The main phase of testing that followed was conducted over eight sessions and was designed to evaluate the tendency of $\mathrm{CS}_{\mathrm{bk}}$ to add to or to inhibit the conditioned suppression to $\mathrm{CS}+$, relative to any similar tendency that might be observed to the presumably neutral $\mathrm{CS}_{\mathbf{n}}$. Each test session involved a single presentation of $\mathrm{CS}+$ in isolation, a presentation of $\mathrm{CS}+$ and $\mathrm{CS}_{\mathrm{n}}$ in simultaneous compound $\left(\mathrm{CS}+/ \mathrm{CS}_{\mathrm{n}}\right)$, and a similar presentation of $\mathrm{CS}+$ and $\mathrm{CS}_{\mathrm{bk}}$ in compound $\left(\mathrm{CS}+/ \mathrm{CS}_{\mathrm{bk}}\right)$. On each day, half the subjects in each group were tested with the sequence $\mathrm{CS}+/ \mathrm{CS}_{\mathrm{n}}, \mathrm{CS}+$, and $\mathrm{CS}+/ \mathrm{CS}_{\mathrm{bk}}$, and the remaining subjects were tested in the reverse order. For each subject, the two daily orders were varied according to an ABBA schedule. The mean withinsession intertrial interval during this phase was 15 min (ranging from 9 to $18 \mathrm{~min}$ ).

Data Analysis. Although barpressing behavior in the presence and absence of stimulation was routinely monitored during the training phase, no attempt was made to extract any assessments of responding to $\mathrm{CS}_{\mathrm{bk}}$ in this phase since (1) the stimulus was, by design, preceded by different events (a US alone or a CS+US sequence) in the two groups, and (2) these preceding events generally produced a suppression that persisted through the duration of $\mathrm{CS}_{\mathrm{bk}}$. Comparative responding to $\mathrm{CS}_{\mathrm{bk}}$ (and to $\mathrm{CS}_{\mathrm{n}}$ ) unobscured and uncomplicated by preceding stimulation was available only during the test phase. Percentage suppression scores to the several CSs and compounds during testing were calculated from the rate of barpressing during the $\mathrm{CS}, \mathrm{b}$, and the 2 -min period immediately preceding the CS, $a$, according to the formula $[(a-b) / a] \times 100$. By this measure, a score of zero indicates no change in the rate of barpressing in the presence versus absence of the CS, and $100 \%$ indicates a complete suppression of responding during the CS compared with the preceding period.

\section{RESULTS}

Since the experimental groups received identical schedules of signaled and unsignaled USs during training, it was presumed that there would be similar levels of excitatory conditioning to the contextual cues in the two cases, which may not have obtained in the Fowler et al. (1984) study. The design of the experiment included no critical test of this assumption, but one expectation would be similar levels of baseline barpressing in the two groups following training. In fact, the group mean pre-CS barpressing rates on each of the nine sessions of testing ranged between 20.6 and 29.7 responses/min for the unsignaled group and between 26.2 and 39.2 for the signaled group, and in no session did the group difference approach statistical reliability [mean $\mathrm{t}(14)=.90$ ]

Whereas CS + quickly came to produce a complete suppression of barpressing during training in all subjects, the backward-trained $\mathrm{CS}_{\mathrm{bk}}$ and the untrained $\mathrm{CS}_{\mathrm{p}}$ had little 
demonstrable effect in either treatment group during the single posttraining session in which they were tested in isolation. It may be notable, in light of other results to be reported, that only $\mathrm{CS}_{\mathrm{bk}}$ of the unsignaled group produced any decrease in barpressing (mean suppression $=2.5 \%$ ), while $\mathrm{CS}_{\mathrm{n}}$ in the same group and $\mathrm{CS}_{\mathrm{bk}}$ and $\mathrm{CS}_{\mathrm{n}}$ of the signaled group all produced some acceleration of responding (mean suppression $=-12.5 \%,-10 \%$, and $-20 \%$, respectively). But none of the differences involved were statistically reliable.

The major results were from the more extensive testing of suppression to $\mathrm{CS}_{\mathrm{bk}}$ and $\mathrm{CS}_{\mathbf{n}}$ in compound with $\mathrm{CS}+$. Figure 1 summarizes the mean percentage suppression to $\mathrm{CS}+/ \mathrm{CS}_{\mathrm{bk}}, \mathrm{CS}+/ \mathrm{CS}_{\mathrm{n}}$, and $\mathrm{CS}+$ alone, over successive blocks of four nonreinforced test sessions, separately for each of the unsignaled (left panel) and signaled (right panel) treatment groups. The first thing that should be apparent is that in all cases there was less suppression to the compounds, in which either $\mathrm{CS}_{\mathrm{bk}}$ or $\mathrm{CS}_{\mathrm{n}}$ was presented with $\mathrm{CS}+$, than to $\mathrm{CS}+$ alone. This overall tendency, which was statistically significant $[F(1,14)$ $=22.72, \mathrm{p}<.01]$ and not reliably different $(\mathrm{F}<1.0)$ in the two groups, could be attributable to an acquired inhibition to $\mathrm{CS}_{\mathrm{bk}}$ which then generalized to $\mathrm{CS}_{\mathrm{n}}$. This interpretation, however, would appear to be disqualified by the fact that the suppression to $\mathrm{CS}+/ \mathrm{CS}_{\mathrm{bk}}$ was not consistently less than that to $\mathrm{CS}+/ \mathrm{CS}_{\mathbf{n}}$. The alternative is to suppose that there was substantial "external inhibition" (Pavlov, 1927) or "generalization decrement" (Hull, 1943 ) in the test compounds relative to the previously rein-

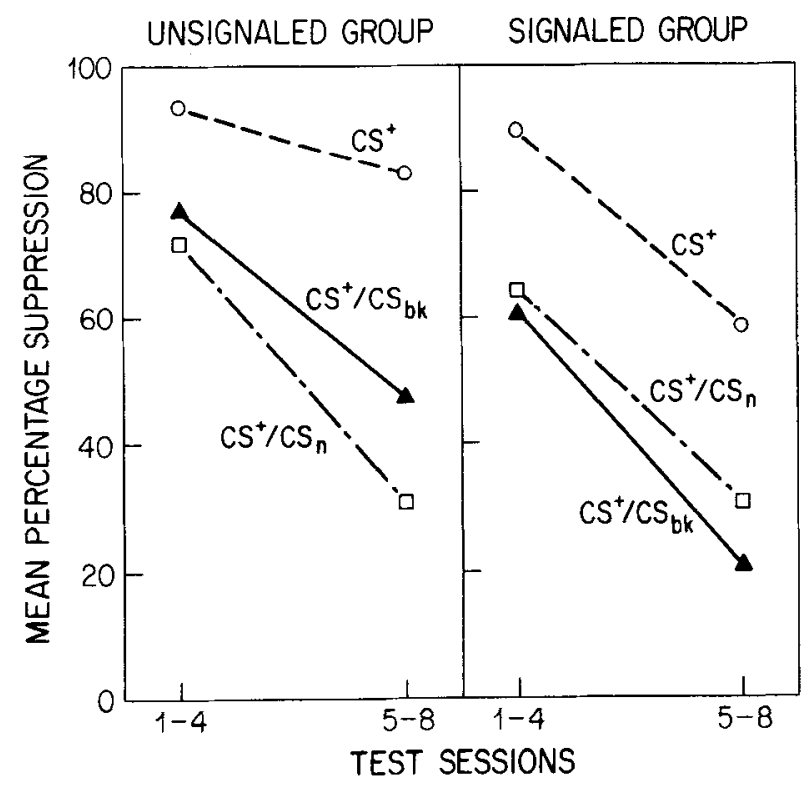

Figure 1. Mean percentage suppression to $\mathrm{CS}+$ in isolation and in simultaneous compound with a "backward" trained cue $\left(\mathrm{CS}+/ \mathrm{CS}_{\mathrm{bk}}\right)$ or an untrained novel cue $\left(\mathrm{CS}+/ \mathrm{CS}_{\mathrm{n}}\right)$, in blocks of four nonreinforced test sessions. The left panel presents the data for a group in which the USs of backward conditioning were unsignaled; the right panel presents comparable data for a group in which such USs were signaled by $\mathrm{CS}+$. forced CS+, and that the deviation of the suppression to $\mathrm{CS}+/ \mathrm{CS}_{\mathrm{bk}}$ from the suppression to $\mathrm{CS}+/ \mathrm{CS}_{\mathrm{n}}$ yields the more appropriate indication of the associative effects of $\mathrm{CS}_{\mathrm{bk}}$. This alternative, which was, of course, anticipated in the design of the experiment, allows a ready interpretation of why the suppression to $\mathrm{CS}+/ \mathrm{CS}_{\mathrm{bk}}$ was in one case greater than that to $\mathrm{CS}+/ \mathrm{CS}_{\mathbf{n}}$ (see unsignaled group in Figure 1) but in another case less than that to $\mathrm{CS}+/ \mathrm{CS}_{\mathrm{n}}$ (see signaled group in Figure 1).

Given the suppression to $\mathrm{CS}+/ \mathrm{CS}_{\mathrm{n}}$ as a baseline (which was not appreciably different in the two groups), it appears from the comparative suppression to $\mathrm{CS}+/ \mathrm{CS}_{\mathrm{bk}}$ that $\mathrm{CS}_{\mathrm{bk}}$ was more excitatory than $\mathrm{CS}_{\mathrm{n}}$ in the unsignaled group and more inhibitory than $\mathrm{CS}_{\mathrm{n}}$ in the signaled group. An analysis of variance of the mean percentage suppression to the two compounds over the eight test sessions confirmed that there was a highly reliable interaction between the treatment groups (signaled vs. unsignaled) and test compounds $\left(\mathrm{CS}+/ \mathrm{CS}_{\mathrm{bk}}\right.$ vs. $\left.\mathrm{CS}+/ \mathrm{CS}_{\mathrm{n}}\right)[\mathrm{F}(1,12)=$ $9.94, p<.01]$. The pattern of greater suppression to $\mathrm{CS}+/ \mathrm{CS}_{\mathrm{bk}}$ than to $\mathrm{CS}+/ \mathrm{CS}_{\mathrm{n}}$ in the unsignaled group was very consistent, occurring in seven of the eight subjects ( $p<.05$, sign test). And the pattern of lesser suppression to $\mathrm{CS}+/ \mathrm{CS}_{\mathrm{bk}}$ than to $\mathrm{CS}+/ \mathrm{CS}_{\mathrm{n}}$ in the signaled group was equally consistent, occurring also in seven of the eight subjects $(\mathrm{p}<.05)$.

Finally, it must be acknowledged that there was some tendency for CS+ alone to produce less suppression in the signaled group than in the unsignaled group, particularly over the final block of four nonreinforced test sessions. The apparent difference, however, was not statistically reliable over the total eight test sessions $[F(1,14)$ $=2.11, \mathrm{p}>.05]$ or over the final block of sessions $[F(1,14)=3.41, \mathrm{p}>.05]$.

\section{DISCUSSION}

The data in comparison of $\mathrm{CS}+/ \mathrm{CS}_{\mathrm{bk}}$ versus $\mathrm{CS}+/ \mathrm{CS}_{\mathrm{n}}$ in the two treatment groups of the present experiment sug gest that backward US-CS pairings are more likely to produce an excitatory CS when the US is unsignaled than when the US is signaled and, complementarily, that the same pairings are more likely to produce an inhibitory CS when the US is signaled than when it is unsignaled. One must be cautious in the interpretation of any single index of associative learning. Thus, in the present case, it is reasonable to question whether the suppression to $\mathrm{CS}_{\mathbf{n}}$ in compound with $\mathrm{CS}+$ provided as appropriate a baseline for detecting potential excitatory learning to $\mathrm{CS}_{\mathrm{bk}}$, in the greater responding to $\mathrm{CS}+/ \mathrm{CS}_{\mathrm{bk}}$, as for detecting potential inhibitory learning, in the lesser responding to $\mathrm{CS}+/ \mathrm{CS}_{\mathrm{bk}}$. It might be conjectured, for example, that the comparison may have been relatively conservative in estimating the degree of inhibitory learning and relatively liberal in estimating the degree of excitatory learning insomuch as $\mathrm{CS}_{\mathrm{n}}$ produced considerable external inhibition whereas $\mathbf{C S}_{\mathrm{bk}}$ may have produced less such effect by virtue of being more familiar. On the other hand, if $\mathrm{CS}_{\mathrm{n}}$ had 
been equally exposed, it may have acquired other special properties, for example, of latent inhibition and habituation, not necessarily shared by $\mathrm{CS}_{\mathrm{bk}}$. There is no doubt that interpretation would be more secure with additional measures, involving not only other baseline estimates of associative neutrality but other converging assessments, for example, a savings/retardation measure, of associative learning. Nonetheless, it appears from the present data that signaling the US in backward conditioning can shift the associative consequences to be less excitatory and more inhibitory. This summary is consistent with the observations of Wagner and Terry (1975), involving differences in excitatory conditioning, but at odds with those of Fowler et al. (1984), involving differences in inhibitory learning. Since the present results and those of Wagner and Terry were obtained in circumstances in which the opportunities for contextual conditioning were held constant, whereas those reported by Fowler et al. were obtained in circumstances in which differences in opportunities for contextual conditioning were confounded with the signaling or not in backward conditioning, it seems reasonable to suppose that the latter confounding may have complicated the Fowler et al. results.

This resolution is of theoretical importance on several grounds. Wagner and Terry (1975) were motivated to explore differential backward conditioning with signaled versus unsignaled USs for the insights that it might provide concerning the nonmonotonic course of associative learning as a function of number of backward conditioning trials. They noted that over a small number of backward pairings of US and CS, conditioned responding to the CS is likely to increase (e.g., Champion \& Jones, 1961; Heth, 1976; Pavlov, 1927), whereas, with more extensive training, conditioned responding is likely to decrease to an untrained level (e.g., Heth, 1976; Smith, Coleman, \& Gormezano, 1969; Spooner \& Kellogg, 1947) and, with sufficient training, the CS is likely to be acted toward as an inhibitory stimulus (e.g., Moscovitch \& LoLordo, 1968; Plotkin \& Oakley, 1975). One interpretation of this pattern is that the initial backward conditioning trials are effectively as well as nominally "unsignaled," and hence producing of excitatory learning, whereas with continued training the same trial events become effectively "signaled" by contextual cues, and hence producing of inhibitory learning that can "extinguish" any CRs and eventually leave the CS inhibitory. If this were the case, an explicitly signaled US, as compared with an unsignaled US, should be less likely to produce excitatory backward conditioning and more likely to produce inhibitory backward conditioning. Wagner and Terry (1975) confirmed the predicted difference in excitatory conditioning. The present experiment witnessed, in addition, the predicted difference in inhibitory conditioning.

That the associative effects of a pairing of CS and US can be modified as a result of signaling the US with another well-trained CS is well known. The so-called blocking effect (Kamin, 1968) is the most common example. In this case, less excitatory learning is produced by a forward, CS-US sequence, if the CS is accompanied by another stimulus previously trained to predict the occurrence of the US. And Wagner and Terry (1975) noted that their observation of diminished excitatory conditioning with a signaled as compared with an unsignaled US could be accepted as indicating that "blocking" occurs as well with backward as with forward pairings of CS and US. It is then theoretically instructive to see that, at least in backward conditioning, the associative result of episodes of pairing of CS and US can not only be excitatorily diminished, but also can be shifted from excitatory to inhibitory as a consequence of signaling the US. This might lead one to question whether the common blocking effect seen with forward CS-US pairings is not partially attributable to inhibitory loadings accruing to the target CS when the US is signaled. We know of no present data that explicitly address this question, but the model of associative learning offered by Wagner (1981) and Mazur and Wagner (1982) anticipates a positive answer.

The model, which has been referred to by the acronym SOP (for "sometimes-opponent-process") assumes, as has been previously indicated, that the pairing of CS and US rather generally presents the opportunity for both excitatory and inhibitory associative learning. And the presumptive mechanism (CS+ instigation of the A2 processing of the US) whereby signaling of a US can reduce excitatory learning (by reducing the necessary $\mathrm{A} 1$ processing of the US) should itself contribute to inhibitory learning. This can presumably occur in a blocking procedure involving forward CS:US pairings, in which the signal is contemporaneous with the target CS, as well as in a blocking procedure, such as in the present case of backward US-CS pairings, in which the signal and target CS are separated by the US. It will require more incisive experimental procedures to evaluate this reasoning adequately. Indeed, it should be acknowledged that the present data, suggesting greater net inhibitory tendencies to $\mathrm{CS}_{\mathrm{bk}}$ in the signaled than in the unsignaled case, are open to numerous alternative interpretations. If CS+ blocks excitatory learning to the target CS (by whatever mechanism), it may uncover the inhibitory learning that also accrues (from whatever source).

\section{REFERENCES}

Champion, R. A., \& Jones, J. E. (1961). Forward, backward, and pseudoconditioning of the GSR. Joumal of Experimental Psychology, 62, 58-61.

Fowler, H., Kleman, M. C., \& Lysle, D. T. (1984). Factors affecting the acquisition and extinction of inhibition suggest a "slave" process. In R. R. Miller \& N. E. Spear (Eds.), Information processing in animals: Conditioned inhibition (pp. 113-150). Hillsdale, NJ: Erlbaum.

HeтH, C. D. (1976). Simultaneous and backward fear conditioning as a function of number of CS-US pairings. Journal of Experimental Psychology: Animal Behavior Processes, 2, 117-129. 
Heth, C. D., \& Rescorla, R. A. (1978). Simultaneous and backward fear conditioning in the rat. Journal of Comparative \& Physiological Psychology, 82, 434-443.

Hull, C. L. (1943). Principles of behavior. New York: AppletonCentury-Crofts.

KAMIN, L. J. (1968). Attention-like processes in classical conditioning. In M. R. Jones (Ed.), Miami symposium on the prediction of behavior: Aversive stimulation. Miami: University of Miami Press.

Keith-Lucas, T., \& Guttman, N. (1975). Robust-single-trial delayed backward conditioning. Joumal of Comparative \& Physiological Psychology, 88, 468-476.

LoLordo, V. M. , FaIrLess, J. L. (1985). Pavlovian conditioned inhibition: The literature since 1969. In R. R. Miller \& N. E. Spear (Eds.), Information processing in animals: Conditioned inhibition (pp. 1-49). Hillsdale, NI: Erlbaum.

MACKINTOSH, N. J. (I 974). The psychology of animal learning. London: Academic Press.

Maler, S. P., Rapaport, P., \& Wheatley, K. L. (1976). Conditioned inhibition and the UCS-CS interval, Animal Learning \& Behavior, 4, 217-220.

Mazur, J. E., \& Wagner, A. R. (1982). An episodic model of associative learning. In M. L. Commons, R. J. Hernstein, \& A. R. Wagner (Eds.), Quantitative analyses of behavior: Acquisition (Vol. 3, pp. 3-39). Cambridge, MA: Ballinger.

Moscovitch, A., LoLordo, V. M. (1968), Role of safety in the Pavlovian backward fear conditioning procedure. Journal of Comparative \& Physiological Psychology, 66, 673-678.

ODLING-SmeE, F. J. (1978). The overshadowing of background stimuli by an informative $\mathrm{CS}$ in aversive Pavlovian conditioning with rats. Animal Learning \& Behavior, 6, 43-51.

Pavlov, I. P. (1927). Conditioned reflexes (G. V. Anrep, Trans.). Oxford: Oxford University Press.

Plotkin, H. C., OAkley, D. A. (1975). Backward conditioning in the rabbit (Oryctolagus cuniculus). Journal of Comparative \& Physiological Psychology, 88, 586-590.
Schull, J. (1979). A conditioned opponent theory of Pavlovian conditioning and habituation. In G. H. Bower (Ed.), The psychology of learning and motivation (Vol. 13, pp. 57-90). New York: Academic Press.

Siegel, S., \& Domjan, M. (1971). Backward conditioning as an inhibitory procedure. Learning \& Motivation, 2, 1-11.

Smith, M. C., Coleman, S. R., \& Gormezano, I. (1969). Classical conditioning of the rabbit's nictitating membrane response at backward, simultaneous and forward CS-US intervals. Journal of Comparative \& Physiological Psychology, 69, 223-231.

Spetch, M. L., Wilkie, D. M., \& PINel, J. P. J. (1981). Backward conditioning: A reevaluation of the empirical evidence. Psychological Bulletin, 89, 163-175.

SPOONER, A., KELlOGG, W. N. (1947). The backward-conditioning curve. American Joumal of Psychology, 60, 321-334.

WAGNER, A. R. (1981). SOP: A model of automatic memory processing in animal behavior. In N. E. Spear \& R. R. Miller (Eds.), Information processing in animals: Memory mechanisms (pp. 5-47). Hillsdale, NJ: Erlbaum.

Wagner, A. R., LAREW, M. B. (1985). Opponent processes and Pavlovian inhibition. In R, R. Miller \& N. E. Spear (Eds.), Information processing in animals: Conditioned inhibition (pp. 233-265). Hillsdale, NJ: Erlbaum.

Wagner, A. R., Rescorla, R. A. (1972). Inhibition in Pavlovian conditioning: Applications of a theory. In R. A. Boakes \& M. S. Halliday (Eds.), Inhibition and learning (pp. 301-336). New York: Academic Press.

WAGNER, A. R., A TerRY, W. S. (1975). Backward conditioning to a CS following an expected versus a surprising UCS. Animal Learming \& Behavior, 3, 370-374.

(Manuscript received August 17, 1984; revision accepted for publication August 22, 1985.) 